\title{
Girls' Multimedia Learning Experiences on Skills Development in Rukwa and Dodoma Regions, Tanzania
}

\author{
Belingtone Eliringia Mariki, PhD candidate \\ Head, Information and Communications Technology Unit \\ Institute of Adult Education, Tanzania \\ *Corresponding author: belingtone.mariki@gmail.com
}

\begin{abstract}
This article is a case study of the Girls Inspire Project (GIP) of the Institute of Adult Education in Rukwa and Dodoma regions in Tanzania. It aimed at exploring the GIP girls' multimedia learning experiences in skills development. Specifically, it focused at exploring on how the girls participate in skills development through multimedia learning as well as their multimedia learning experiences. The study employed exploratory research design with qualitative research approach. It involved 32 girls by snowball sampling. The researcher analyzed data using content analysis. Findings indicate that; the girls participated in multimedia learning using LCD projectors, conducted discussions and later, practical sessions. Subsequently, they practiced hands-on skills in groups, with reference to learning contents and facilitators' guidance. The study concludes that the girls had a commendable multimedia learning experience on skills development. However, based on the offline learning challenges observed, the researcher recommends a feasibility study for online multimedia learning in rural parts of Tanzania prior to establishing similar interventions so as to enhance flexible access to learning contents and effective learning experiences.
\end{abstract}

Key words: Multimedia learning, multimedia learning contents, girls' experiences, skills development

\section{Introduction}

Based on the increased use of technology in today's world and its appreciation in various socio-economic development and educational programs, the importance of multimedia learning cannot be overemphasized. As a result, it cannot be ignored that multimedia is a driving force towards promoting knowledge, skills and competences to learners. It is generally accepted that multimedia has a great contribution toward learning especially in adding quality of the content and enhancing active participation among learners (Abas, Osman, Kumar, \& Thangapragasam, 2007; Richards, Dooley, \& Lindner, 2004 as cited in Chaturvedi, 2010). Similarly, several authors argue that multimedia technology adds value to learning content and therefore results to a better understanding among learners (Abas et al., 2007; Kaputa \& Mpezeni, 2016;
Kulasekara, Jayatilleke, \& Coomaraswamy, 2011; Mayer, 2002).

According to Heinich, Molenda, Russel and Smaldino (1996) as cited in Chaturvedi (2010), "multimedia emerged in the 1950s and was commonly referred to [as a digital content] that combined at least two media formats such as text and video or audio at one time" (p. 40). Today various scholars view multimedia as a set of digital learning content designed and developed using a combined form of various media such as animations, audio, video, text, and graphics (Lau, Yen, Li, \& Wah, 2013; Li \& Lau, 2011; Mariki, 2014; Mtebe, Mbwilo, \& Kissaka, 2016). Hence, multimedia learning as used in this study means a learning process that employs the use of a digital content made up of combinations of various media (Mayer, 2014; Sankey, Birch, \& Gardiner, 2010). In line with this meaning, 
multimedia learning contents as used in this study are the multimedia-aided learning materials designed and developed for learning purposes. Thus, the study focuses on girls' experiences in that contextual meaning in Tanzania.

This study basically is a case study of Girls Inspire Project (GIP); a project implemented by the Institute of Adult Education (IAE) in Tanzania since 2017 to 2019 aiming at using multimedia learning in training girls aged between 10 to 25 years, who dropped out of formal schooling system due to pregnancy and early marriages. The multimedia learning was aimed at training these girls on skills development areas including environment, HIV AIDS, gender, communicating in business, arithmetic, batik making, liquid soap making, and bar soap making. The intervention was considered an alternative pathway to the girls as they had already missed the opportunity of continuing with formal schooling. GIP used multimedia learning in training the targeted girls as it was a flexible means of learning that suited the context of the girls who were already at home as mothers and wives, with multiple family responsibilities. Thus, according to Mohamed and Victor (2012) and Reuben (2015), such learners require an open learning mode so as to study while attending their other responsibilities. In that regard, multimedia learning appeared to suit the context due to its flexible nature and ability to enhance effective learning. IAE implemented the project in Kalambo and Nkasi Districts of Rukwa Region and Kongwa and Bahi Districts of Dodoma Region whereby a selected ward from each district had two open learning centres. According to the GIP focal person, S. G. Mwita, (personal communication, July 2 , 2019), the project aimed at enrolling 1,500 girls but eventually exceeded the target by reaching 1,981 girls.

Literature shows that the use of multimedia enhances effective learning and understanding than the use of text alone (Mayer, 2014; Thomas \& Israel, 2014). Various literature show that with multimedia contents, learning becomes active and interactive; learners tend to be attracted with animations, sounds, pictures, and videos integrated therein (Kessy, 2016; Malik \& Agarwal, 2012; Mtebe, Kibga, Mwambela, \& Kissaka, 2015). According to Babiker (2015) and Mayer (2014) multimedia learning contents allows learners to understand better because they see, hear and see what is being presented. A famous Chinese Philosopher,
Confucius once said, "If all I do is hear, I will forget. If I hear and see, I will remember. If I hear, see and do, I will understand" (Khalid \& Nuhfer-halten, 2011, p. 8). The ideas by Confucius are in other words, signifying the power of multimedia learning contents in enhancing better understanding. Similarly, the cognitive theory of multimedia learning advocates that human mind understands better the information that is delivered in the form of words and pictures. According to the theory, human mind processes words and pictures to meaningful sounds and images organized in verbal and pictorial interpretation and integrates it with the existing prior knowledge (Mayer, 2014). Such process makes an effective learning and results to a better understanding. Multimedia learning therefore brings together teachers and students at a closer proximity as it fills the gap between the two by means of the interactive contents being delivered. Furthermore, literature shows that effective multimedia allows learners to actively interact with learning contents by means of animations control as they can play, pause, unpause, skip or replay sections they like (Abas et al., 2007; Hasler, Kersten, \& Sweller, 2007; Kulasekara et al., 2011; Mohd Elmagzoub, 2015). This enhances not only active learning among learners but also effective learning and better understanding (Kessy, 2016).

Empirical studies show that various learners from different places appreciate multimedia learning based on their own experiences. Experience by learners at the Open University of Malaysia who were subjected on multimedia learning for research purposes, shows that they were highly motivated because the technology made learning interactive, allowed better understanding and simplified learning as opposed to print media technology (Abas et al., 2007). Similarly, a study by Kulasekara et al. (2011) in Sri Lanka shows that learners at the Open University of Sri Lanka considered multimedia learning helpful as it simplifies and stimulates learning. The study shows that learners appreciate a combination of the media used in the learning contents as it included animations, graphics, audio, sounds, text and video. Such combination allowed media to complement to each other in a manner that promoted a better understanding. Also, the study shows that learners had control over animations and could navigate through the learning contents. The experiences indicated by Kulasekara et al. (2011) and Abas et al. (2007) in Sri Lanka and 
Malaysia respectively, are similar to the ones indicated in the study by Tablatin, Patacsil, and Cenas (2016) in Philippines where learners appreciate multimedia learning. This study shows that learners could see PDF text on screen and hear audio narrations, something which enhanced better understanding among them. Similarly, at the University of Dar es Salaam in Tanzania, learners commended the effectiveness of multimedia learning contents provided in compact discs (CDs) as it included their course contents that were difficult to access online. Although the learners complained of the outdated learning contents uploaded in the online university learning system, they were happy to have had "an alternative means to access learning resources" through multimedia learning contents on CDs (Mtebe \& Raphael, 2013 p.133).

Based on the experiences indicated above, this study intended at exploring multimedia learning experiences among the girls involved in GIP so as to add knowledge on the study area at the lower levels of out of school systems. Most of studies have been conducted at tertiary levels thus, the importance of the current study cannot be overemphasized (see Abas et al., 2007; Kulasekara et al., 2011; Mtebe \& Raphael, 2013; Ranga \& Mhaka, 2016; Tablatin et al., 2016). Correspondingly, there are no studies conducted in Tanzania at the context of the girls thus, little is known on how the out-of-school girls experience multimedia learning at lower levels of education in an open learning environment. In this regard, the current study therefore aimed towards exploring the girls' multimedia learning experiences in skills development training at the selected wards of Rukwa and Dodoma regions in Tanzania. Specifically, the study focused on determining the girls' participation in skills development through learning and their experiences during multimedia learning. Subsequently, the research questions that guided the study are: (i) how do girls participate in multimedia learning for skills development? and, (ii) what are the girls' multimedia learning experiences in skills development?

\section{Research Methodology}

This section presents the methodology used. It includes such items like research design, population and sampling, validity and reliability, data analysis and ethical considerations.

\section{Research Design}

The study employed exploratory research design as advocated by Maritim and Mushi (2012). The researcher selected this design because there are limited studies conducted in the current research area (see Creswell, 2014; Saunders, Lewis, \& Thornhill, 2009). Based on the fact that this study was meant not for generalizing results, qualitative research approach was applied (Creswell, 2014; Nyaruwata, 2013).

\section{Population and Sampling}

Upon saturation of data (Creswell, 2014), the researcher reached 32 study participants drawn from the study population that comprised of the girls involved in the GIP from Bahi and Kongwa Districts in Dodoma region and Kalambo and Nkasi Districts in Rukwa region. Through snowball sampling technique, the researcher reached and conducted interviews and Focus Group Discussions (FGD) to the 32 girls of the GIP. The sampling method was used because some of the girls were difficult to trace (Tshuma \& Mafa, 2013). Table 1 presents the participants' distribution by their respective wards in Rukwa and Dodoma regions.

Table 1: Participants' distribution by wards

\begin{tabular}{lccccc}
\hline \multirow{2}{*}{ Participants } & \multicolumn{2}{c}{ Rukwa Wards } & \multicolumn{4}{c}{ Dodoma Wards } & \multirow{2}{*}{ Total } \\
& Chala & Msanzi & Bahi & Sejeli & \\
GIP Girls & 9 & 8 & 8 & 7 & 32 \\
\hline
\end{tabular}

\section{Validity and Reliability}

With reference to the existing literature (Creswell 2014; Lincoln \& Guba 2011), the researcher used interview and FGD methods of data collection to ensure validity of data. Consequently, the researcher conducted FGDs to all the interviewed participants so as to ensure accuracy and credibility of data. Subsequently, for reliability purposes, the researcher pretested the data collection instruments at Msanzi ward in Rukwa to 8 girls and 2 facilitators. The pretest involved also 2 multimedia production team members from IAE. To ensure reliability of the instruments, the researcher selected the pretest participants only from the study population (Creswell, 2014; Tshuma \& Mafa, 2013). The pretest results depicted not unexpected results thus, the researcher maintained the instruments.

\section{Data Analysis}

The researcher analyzed the data from interview and FGD methods using content analysis (Bengtsson, 2016; Cho \& Lee, 2014) in which, he had to listen to it from a recorded audio files; transcribe to make meaning out of it (Tshuma \& Mafa, 2013) and annotate it into respective themes set on a table designed on a Microsoft Excel sheet. The excel 
sheet enhanced smooth data retrieval and presentation as for a case of excerpts, comparisons and logical reasoning.

\section{Ethical Considerations}

The GIP was implemented by IAE in the selected districts in Rukwa and Dodoma regions. As such, the researcher requested approval from IAE and the respective local government authorities at the study areas prior to data collection as advocated by literature (see Graham, Phelps, Nhung, \& Geeves, 2014; Vreeman et al., 2012; Wilson \& Wilks, 2013). Similarly, the researcher complied to research ethics by introducing the research purpose to participants and seeking consent from them as well as their families prior to interviews (Vreeman et al., 2012). Furthermore, pseudonyms were used in this study in order to hide the identity of the participants quoted in this study at the findings section.

\section{Findings of the Study}

This section presents findings for the stated research questions showing excerpts derived from interviews. Subsequently, it presents findings from the FGDs as explained by the research participants. Findings are thus in two sections viz., girls' participation and girls' experiences. For anonymity reasons, pseudonyms are used accordingly for individual participants quoted in this section.

\section{Girls' participation in multimedia learning for skills development}

Girls' participated in skills development by viewing the multimedia learning contents that were preinstalled in the computers distributed to the learning centres in the GIP wards. The girls said that their facilitators projected the learning contents on a wall in a classroom using liquid crystal display (LCD) projectors for them to view. Some facilitators reported to have covered the room windows with curtains to protect it from sunlight and allow clear view on the projected contents. One girl, for instance, said, "I had to cover the room windows to enhance the conducive learning environment. The room needed to be a little bit darker for the projected contents to be seen clearly" (Gaya).

The study participants further reported that the multimedia learning involved theory and practical sessions. One participant Chausiku, for instance said, they "sat in the classroom, viewed the displayed contents, discussed and did the practical later". Another participant said,
We were listening to the whole video and later on did the practical part with our facilitator. Also, in Gender, Environment, HIV AIDS, Arithmetic and Communication learning contents, like in the hands-on skills contents, we listened for the whole content before discussions and sharing of experiences. We had time to share real cases from families and our neighbourhood relating to the subject matter (Didia).

Several learners pointed out that they had a chance to ask questions and conduct discussions during or after a learning content. As for the case of Gender, HIV AIDS and communication contents, the learning experience was very interesting. There was a long session of discussions and questions because most of learners raised real issues relating to gender discrimination, sexual abuse and customer care skills. Other learners added that clarifications from their facilitator on the multimedia content were exciting and engaging to further discussions. A facilitator from one of the centres said,

In Gender and HIV AIDS, I played the content and thereafter engaged learners in discussion in which they shared their own real cases relating to what they have just seen on screen. The discussions among learners were very lively and, in some cases, I had to replay some parts upon their request (Manuu).

Several other girls also said that they felt comfortable when participated in skills training sessions as the facilitators used presentation and discussion approach so as to allow viewing of the multimedia learning contents prior to discussions and practical sessions. With regard to hands-on skills contents, learners said that they had a day for just a theoretical part, followed by a day for practical session. Adding to this, one of the girls Sambu, said that the facilitators' approaches encouraged active participation among them. She also added that facilitators made their participation even more welcoming saying, "facilitators mingled with us as their colleagues...there was no such a relationship like teacher-student but rather a collegial and cordial". Another girl Imbwa, added that the experience made them participate comfortably in the whole learning process.

Another girl Lexus said that their participation in multimedia learning was flexible and suitable to 
their schedules. The learners said that learning was conducted in the evenings where most of them could attend and there were no strict time tables. A girl named Pia said they had a room to reschedule sessions. She said, "in some days we agreed to come early especially for practical sessions". Also, the learning environment encouraged girls' participation regardless of their individual problems. One of the girls said,

Some of us came with our babies in the classroom and they were crying at some points but the facilitator would always find a way to calm them down. There was a time the facilitator helped me to babysit my baby outside the classroom and let me continue with the ongoing learning session (Lexus).

\section{Girls' multimedia learning experiences in skills development}

The girls' testimonials show that they had an experience that made them interactive and active in both theory and practical sessions during multimedia learning. In commenting about their experience on the sessions, one of the girls Lexus said that since they "had a laptop computer and projector supplied for the GIP [in which their] facilitators used to connect the projector on the laptop and play the content" then they were able to pause and unpause the multimedia learning content at any point whenever needed. Adding to this, another girl said, "sometimes we had to replay a particular segment for taking notes on what was presented. In short, we were able to move back and forth as we wanted" (Sala). During one of the FGDs, it was argued that not all the girls could navigate through the learning contents as most of them were computer illiterates. Responding to this, one of the interviewed girls said,

For most of us it was the first time to see that thing displaying video on the wall...We could not have navigated through the multimedia learning content even if needed but our colleagues did it for us and we were able to follow through (Gunia).

Talking about the practical sessions, several girls said that their multimedia learning experience in batik, bar soap and liquid soap making was interesting as they could practice what they saw on the projected contents and see results of what they made. One of the girls Awichi, said that at some cases they could not remember some requirements in making some products but managed to work it out using their referencing notes. Another girl Ena said, "we did our practical works in individual groups. Though guided by our facilitators, we were also referring to our notes we captured from the multimedia learning contents". Adding to this, another girl said,

There were some debates during the process regarding steps, measurements and time needed for a particular task but this was quickly settled as most of us were referring to our notes taken from the multimedia learning contents. Also, a facilitator was always there to instantly settle the mix-ups (Have).

Furthermore, several girls said that they did practical sessions in team work whereby each one had a role to play. For instance, facilitators would ask some of the girls to identify and prepare materials needed for bar soap making, then ask others to identify the next step as well as demonstrating it. Thereafter, other girls would again demonstrate the step that follows, followed by others who would continue to the next part and so forth, so that everyone would finally participate. One girl who appeared to be very conversant with all practices had this to say:

The practice of the skills taught was a collective assignment in which we all worked as a team. I can recall the bar soap making practical in which our facilitator allowed us to practice on our own under her supervision. Some of us in my group prepared required materials and two of us who had gloves and mask on, mixed the prepared chemicals and materials as stipulated in the learning content. There was a hectic moment experienced because bar soap making needed timing precision and physical energy, particularly in stirring the end product solution. We went on step by step till the end of the process and each one of us had a chance to participate at one stage or the other (Sorina).

\section{Difficulties Experienced}

When responding to this aspect, several girls said that there were no serious difficulties spotted during the multimedia learning process. One of the girls Anda said that, "there were no difficulties experienced...everything was okay with the learning". Another girl Taga said, "it is not easy to locate difficulties experienced because all of us were 
excited with multimedia learning". She added, "there were no experiences that I could list as difficulties because all theoretical and practical sessions were well delivered".

Notwithstanding the above information, Kisu, one of the girls who happened to be advanced in information technologies said; multimedia learning contents were accessible offline and only at the learning centre, such that, no one could have accessed them online at home, if wanted to do so. She added that, since there were no chances for accessing the learning contents at home, then learners had to consult facilitators for accessing it at the learning centres. However, other girls said that this was not a difficulty in their context because none of them had gadgets to use at home.

Another girl pointed out that, there was no room for instant interaction with the presenter on the multimedia learning content displayed:

The learning content was not a live presentation. We could not ask questions to the presenter on the screen but instead, facilitators at the centres were answering our questions. I believe the presenter on the multimedia content could have responded better to our questions although our facilitators were as good (Awichi).

Other girls pointed out that in their centre they used Head teachers' office as a classroom and this was a bit challenging to the learners because the room happened to be too small for everyone to be accommodated inside. The following statements clarify:

Our multimedia sessions were conducted in the Head teacher's office at our centre because it was the only room with electric power supply at the school. Space was therefore limited and we overcrowded the room to the extent that some of us had to view the [projected] content from outside (Sisimi).

Those who viewed from outside the Head teacher's office could hear from the learning content displayed but with some noise interferences of the school surroundings. Some of the girls were struggling to listen to what was being said in the learning content.
This however did not affect them much because during practical sessions, there was a collective practice in which facilitators ensured understanding and participation by everyone (Anze).

\section{Discussion of Findings}

Findings imply that multimedia learning enhanced the skills development process among the girls in an offline environment, as facilitators used the learning contents pre-installed in the computers. This ensured content delivery without a need for Internet services (cf. Mtebe \& Raphael, 2013) and computer gadgets like; iPads, tablets, smartphones, and laptops by learners, unlike in online learning environment (Chaturvedi, 2010; Tablatin et al., 2016). Such experiences shows that the learning environment allowed active and comfortable learning as it considered the girls' rural settings where there was no reliable Internet services (see also Bhalalusesa, Lukwaro, \& Clemence, 2013; Nihuka \& Voogt, 2011).

Furthermore, as indicated in the findings, the facilitators ensured conducive learning environment and allowed learners to first view the learning content, discuss and later participate in practical sessions. Such whole process made the girls to learn actively and comfortably. Also, the discussions done every after viewing a multimedia learning content, stimulated sharing of prior knowledge and real-life experiences by the girls and eventually enhanced broader understanding among them. Furthermore, findings indicate flexibility of the multimedia learning intervention in terms of scheduling of learning sessions and inclusion of all girls regardless of their marital and motherhood status as opposed to formal schooling (see also Reuben, 2015; Tichauya, Alexander, Paul, \& Emanuel, 2012). For instance, facilitating the girls' attendance to the multimedia learning sessions with their babies, did not only signify open learning but also facilitated effective participation among them.

Based on the findings, it is evident that the girls experienced active learning as they had control over animations on the learning contents and opportunity to practice the hands-on skills on their own. They also had time to discuss, share ideas and work in groups to make the products trained on. This signifies the ideas on literature stated earlier that multimedia contents that allow learners' control over animations, makes learning attractive, 
interactive and result to better understanding (see Abas et al., 2007; Kulasekara et al., 2011; Li \& Lau, 2011; Mohd Elmagzoub, 2015).

As indicated in the findings, the study participants indicated that there were minor difficulties experienced that did not however, affect their participation and learning process in general. Notwithstanding the argument, the difficulties mentioned cannot be ignored as they are calling for improvements and even further research. The issues pointed out like; inability to access contents online and interact live with presenters as well as the use of the Head teacher's office due to lack of electric power supply in the classrooms, are things that needs attention to future interventions. When such issues are attended, online learning would increase flexibility and interaction between learners and presenters (see Tablatin et al., 2016). However, the challenge of poor connectivity in rural areas of the country might become an obstacle in accessing multimedia online learning (see Bhalalusesa et al., 2013; Nihuka \& Voogt, 2011).

\section{Conclusions and Recommendations}

This section gives conclusions based on study findings that resulted from data analysis. It also gives recommendations for future interventions and further studies.

\section{Conclusions}

Based on the findings, it is clearly seen that the girls had commendable experience in multimedia learning on skills development. The girls commended their learning experiences indicating that they were able to develop hands-on skills in liquid soap, batik and bar soap making as a result of multimedia learning. The combination of various media in learning contents made them imitate easily the skills demonstrated as it facilitated the practical sessions. Furthermore, the presence of facilitators mediating multimedia learning, made learning more interactive and meaningful though at an offlineopen-learning environment. Thus, multimedia learning in an offline-open-learning environment results to better experience among girls in skills development especially when mediated by facilitators at the learning centres.

\section{Recommendations}

With reference to the findings, the researcher recommends for future girls' multimedia learning interventions to adopt the experiences stipulated in this study. However, further study is needed to assess the feasibility of online multimedia learning in the rural parts of Tanzania, prior to such interventions, so as to ensure flexible accessibility to learning contents and enhance effective multimedia learning experiences for skills development among girls.

\section{References}

Abas, Z. W., Osman, R., Kumar, P. R., \& Thangapragasam, S. (2007). Effectiveness of multimedia courseware design: Towards quality learning in ODL. Proceedings of 21st Annual Conference of Asian Association of Open Universities, 29-31.

Babiker, M. E. A. (2015). For effective use of multimedia in education, teachers must develop their own educational multimedia applications. Turkish Online Journal of Educational Technology. Retrieved from http://www.tojet.net/articles/v14i4/1446.pdf

Bengtsson, M. (2016). How to plan and perform a qualitative study using content analysis. NursingPlus Open, 2, 814. https://doi.org/10.1016/i.npls.2016.01.001

Bhalalusesa, R., Lukwaro, E. E. A., \& Clemence, M. (2013). Challenges of Using E-learning Management Systems faced by the Academic Staff in Distance Based Institutions from Developing Countries: A Case Study of the Open University of Tanzania. Huria Journal, Open University of Tanzania, 14(1), 89-110.

Chaturvedi, V. (2010). A Critical Investigation of Scope, Opportunities and Challenges in Online Distance Learning Education System in Indian Perspective: A Futuristic Outlook for Scaling Quality Education. Symbiosis International Research Journal on Open \& Distance Learning, 37-46. Retrieved from http://www.scdl.net/

Cho, J. Y., \& Lee, E. (2014). Reducing Confusion about Grounded Theory and Qualitative Content Analysis : Similarities and Differences. The Qualitative Report, 19(32), 1-20.

Creswell, J. W. (2014). Research Design: Qualitative, 
Quantitative, and Mixed Methods Approaches (4th ed.). Washington DC: SAGE Publications, Inc.

Graham, A. P., Phelps, R. A., Nhung, H. T. T., \& Geeves, R. (2014). Researching with Children in Vietnam: Cultural, Methodological and Ethical considerations. Qualitative Research, 14(1), 37-60.

https://doi.org/10.1177/1468794112455038

Hasler, B. S., Kersten, B., \& Sweller, J. (2007). Learner Control , Cognitive Load and Instructional Animation. Applied Cognitive Psychology, 729(21), 713-729. https://doi.org/10.1002/acp

Kaputa, T. M., \& Mpezeni, L. (2016). Perceptions of open and distance learners towards modules on $C D$ : the zimbabwe open university experience. International Journal of Multidisciplinary Academic Research, 4(1), 111.

Kessy, H. C. F. (2016). Differential effectiveness of plain and multimedia enriched sex education instructional materials on secondary school students' academic performance in Tanzania (Open University of Tanzania). Retrieved from http://repository.out.ac.tz/1725/1/HYASINTA_KESSY _PhD_THESIS.pdf

Khalid, A., \& Nuhfer-halten, B. (2011). Enhancing Learning at the Polytechnic University: Interactive Classroom Techniques. 3rd Polytechnic Summit. Retrieved from http://facultyweb.kennesaw.edu/akhalid2/Con ference12.pdf

Kulasekara, G. U., Jayatilleke, B. G., \& Coomaraswamy, U. (2011). Learner perceptions on instructional design of multimedia in learning abstract concepts in science at a distance. Open Learning, 26(2), 113-126. https://doi.org/10.1080/02680513.2011.56745 9

Lau, R. W. H., Yen, N. Y., Li, F., \& Wah, B. (2013). Recent development in multimedia e-learning technologies. World Wide Web, 17(2), 189-
198. https://doi.org/10.1007/s11280-0130206-8

Li, F. W. B., \& Lau, R. W. H. (2011). Emerging technologies and applications on interactive entertainments. Journal of Multimedia, 6(2), 107-114.

https://doi.org/10.4304/jmm.6.2.107-114

Lincoln, Y. S., \& Guba, E. G. (2011). Paradigmatic controversies, contradictions, and emerging confluences, revisited. The Sage handbook of qualitative research.

Malik, S., \& Agarwal, A. (2012). Use of Multimedia as a New Educational Technology Tool-A Study. International Journal of Information and Education Technology, 2(5), 468-471. https://doi.org/10.7763/IJIET.2012.V2.181

Mariki, B. E. (2014). Teachers' experiences in educational multi-media content development: The case of Tanzania's institute of adult education. Turkish Online Journal of Distance Education, 15(4), 181-188. https://doi.org/10.17718/tojde.18424

Maritim, E. K., \& Mushi, H. M. K. (2012). Mobile Technologies for Enhancing Distance Learning in Tanzania: An Exploratory Study. Huria Journal of the Open University of Tanzania, 13(Special Issue), 123-138. Retrieved from https://www.out.ac.tz/page.php?m=179

Mayer, R. E. (2002). Multimedia learning. Psychology of Learning and Motivation, 41, 85-139.

https://doi.org/https://doi.org/10.1016/S0079 $-7421(02) 80005-6$

Mayer, R. E. (2014). Cognitive Theory of Multimedia Learning. In R. E. Mayer (Ed.), The Cambridge Handbook of Multimedia Learning (pp. 31-48). Santa Barbara: Cambridge University Press.

Mohamed, A. A., \& Victor, M. A. . (2012). The Role of Open and Distance Learning in Promoting Professional Training and Development in Tanzania. A Case Study of The Open University Tanzania. Huria: Journal of the Open University 
of Tanzania, 13(Special Issue), 395-400. Retrieved from https://www.out.ac.tz/page.php?m=179

Mohd Elmagzoub, A. (2015). For effective use of multimedia in education, teachers must develop their own educational multimedia applications. Turkish Online Journal of Educational Technology, 14(4), 62-68. Retrieved from http://www.scopus.com/inward/record.url?ei $\mathrm{d}=2$-s2.084943570465\&partnerID $=40 \& \mathrm{md} 5=\mathrm{be} 0 \mathrm{~d} 622 \mathrm{fa}$ 0edf700b0e53f81cbe1a0c3

Mtebe, J. S., Kibga, E. Y., Mwambela, A. A., \& Kissaka, M. M. (2015). Developing Multimedia Enhanced Content to Upgrade Subject Content Knowledge of Secondary School Teachers in Tanzania. Journal of Learning for Development - JL4D, 2(3), 29-44. https://doi.org/10.1007/s00894-012-1733-4

Mtebe, J. S., Mbwilo, B., \& Kissaka, M. M. (2016). Factors Influencing Teachers' Use of Multimedia Enhanced Content in Secondary Schools in Tanzania. International Review of Research in Open and Distance Learning, 17(2), 65-84.

Mtebe, J. S., \& Raphael, C. (2013). Students' experiences and challenges of blended learning at the University of Dar es Salaam, Tanzania. International Journal of Education and Development Using Information and Communication Technology (IJEDICT), 9(3), 124-136.

Nihuka, K. A., \& Voogt, J. (2011). Instructors and Students Competences, Perceptions and Access to E-learning Technologies: Implications for E-learning Implementation at the Open University of Tanzania. International Journal on E-Learning, 10(1), 63-85. Retrieved from http://editlib.org/p/32413

Nyaruwata, L. T. (2013). Quantitative, Qualitative, and Mixed Methods Approaches to Research. In S. M. Tichapondwa (Ed.), Preparing your Dissertation at a Distance: A Research Guide (pp. 101-113). Retrieved
http://www.sadc.int/files/3713/7821/2867/Dissert ation_PDF.pdf

Ranga, D., \& Mhaka, S. (2016). Role of information and communication technology ( ICT ) in open and distance learning (ODL): an analysis based on Zimbabwe Open. Open and Distance Learning Journal, (Special Issue), 102-117. Retrieved from http://www.iodlj.zou.ac.zw/ejournal/index.php /journal/article/view/123/127

Reuben, N. (2015). Some Reflections on ODL Practice at the Open University of Tanzania. Saarbrücken: Scholar's Press.

Sankey, M. D., Birch, D., \& Gardiner, M. (2010). Engaging students through multimodal learning environments : The journey continues. Proceedings Ascilite Sydney 2010, (Bradwell 2009), 852-863.

Saunders, M., Lewis, P., \& Thornhill, A. (2009). Research Methods for Business Students (5th ed.). Harlow: Financial Times Prentice Hall.

Tablatin, C. L. S., Patacsil, F. F., \& Cenas, P. V. (2016). Design and development of an information technology fundamentals multimedia courseware for dynamic learning environment. Journal of Advances in Technology and Engineering Research, 2(6). https://doi.org/10.20474/jater-2.6.5

Thomas, O. O., \& Israel, O. O. (2014). Effectiveness of Animation and Multimedia Teaching on Students ' Performance in Science Subjects. British Journal of Education, Science \& Behavioural Science, 4(2), 201-210.

https://doi.org/https://doi.org/10.9734/BJESBS/20 $14 / 3340$

Tichauya, C. H., Alexander, C. R., Paul, M., \& Emanuel, D. (2012). The Forgotten Tribe in ODL Systems: Challenges Faced by Visually Impaired Students in Institutions of Higher Learning. Huria: Journal of the Open University of Tanzania, 13(Special Issue), 410-421. Retrieved from https://www.out.ac.tz/page.php?m=179 
Tshuma, R., \& Mafa, O. (2013). Research Designs. In S. M. Tichapondwa (Ed.), Preparing your Dissertation at a Distance: A Research Guide (pp. 114-137). Vancouver: Virtual University For Small States of the Collonwealth.

Vreeman, R., Kamaara, E., Kamanda, A., Ayuku, D., Nyandiko, W., Atwoli, L., ... Braitstein, P. (2012). Community Perspectives on Research Consent Involving Vulnerable Children in
Western Kenya. Journal of Emprirical Research on Human Research Ethics, 7(4), 44-55. https://doi.org/10.1525/jer.2012.7.4.44

Wilson, K., \& Wilks, J. (2013). Research with Indigenous Children and Young People in Schools: ethical and methodological considerations. Global Studies of Child, 3(2), 142-152.

https://doi.org/10.2304/gsch.2013.3.2.142 